\title{
EFFECTS OF STAPHYLOCOCCAL PRODUCTS ON LOCO- MOTION AND CHEMOTAXIS OF HUMAN BLOOD NEUTROPHILS AND MONOCYTES
}

\author{
R. J. Russell, P. C. Wilkinson, the late R. J. McInroy, S. McKay, \\ A. C. MCCartneY* and J. P. ARbuthNOTT* \\ Department of Bacteriology and Immunology, Western Infirmary, and \\ * Department of Bacteriology, Royal Infirmary, University of Glasgow
}

ACUTE staphylococcal infection is characterised by a polymorphonuclearleucocyte host-response, and since Metchnikoff's time the leucocytes have been thought to reach the lesion by chemotactic migration; but surprisingly few people have examined staphylococci to determine whether they produce chemotactic factors or to define the nature of any such agents. Chemotactic factors may fall into two classes: (i) those acting directly on the responding cell and termed "cytotaxins" according to the nomenclature of Keller and Sorkin (1967), and (ii) those that are not directly chemotactic but, when incubated with serum, activate enzyme systems such as complement and cause release of chemotactic peptides. These indirectly acting factors have been named " cytotaxigens" (Keller and Sorkin, 1967).

Cytotaxins for neutrophils have been reported in crude culture filtrates of Staphylococcus albus (Keller and Sorkin, 1967, Ward, Lepow and Newman, 1968). Walker, Barlet and Kurtz (1969) are the only workers who have attempted to purify cytotaxins from staphylococci. They isolated a non-dialysable cytotactic fraction from Staphylococcus aureus; it yielded six bands on electrophoresis, but the authors did not establish which of these was associated with the chemotactic activity.

Generation of cytotaxigenic activity when staphylococci were added to serum or plasma was demonstrated by Ryan and Hurley (1966) and by Keller and Sorkin (1967). Staphylococcal protein $\mathrm{A}$ has been reported to generate similar activity for neutrophils by becoming bound to the Fc fragment of IgG, thus fixing complement (Harvey et al., 1970). Cytotaxigenic activity for neutrophils has also been attributed to staphylococcal enterotoxin B in the presence of serum (Craig et al., 1971).

Two studies suggest that staphylococci and certain staphylococcal products can also inhibit chemotaxis. Woodin (1971) has emphasised the action of leucocidin as an inhibitor of various neutrophil functions including chemotaxis, but detailed experimental evidence of the action of leucocidin on leucocyte locomotion has not been published. Weksler and Hill (1969) isolated from virulent strains of $S$. aureus a cell-wall mucopeptide that inhibited neutrophil migration in vitro without affecting the viability of the cells.

The information on the effects of staphylococci and other pathogens on leucocyte locomotion is clearly inadequate. If staphylococci have the potential to produce both chemotactic factors and inhibitors, the whole organisms and their filtrates are likely to contain

Received 6 Nov. 1975; revised version accepted 25 Feb. 1976.

J. MED. MICROBIOL.-VOL. 8 (1975

433 
TABLE I

Strains of staphylococci used

\begin{tabular}{|c|c|}
\hline Strain no. & Description \\
\hline $\begin{array}{l}\text { SM1* } \\
\text { SM2 }\end{array}$ & $\begin{array}{l}\text { No. NCTC7121 (Wood 46); a classical and toxigenic strain } \\
\text { No. NCTC10649 (Morris capsulate strain); from hand } \\
\text { laceration }\end{array}$ \\
\hline SM3 & $\begin{array}{l}\text { From skin of 10-year-old child with superficial lesions. Phage- } \\
\text { group II }\end{array}$ \\
\hline $\begin{array}{l}\text { SM6 } \\
\text { SM9 } \\
\text { SM10 } \\
\text { SM14 }\end{array}$ & $\begin{array}{l}\text { From urinary-tract infection. Coagulase negative } \\
\text { From knee abscess of a 1-year-old child } \\
\text { From sputum of a } 2 \text {-year-old child with cystic fibrosis } \\
\text { From conjunctiva of a } 21 \text {-year-old woman suffering from }\end{array}$ \\
\hline $\begin{array}{l}\text { SM15 } \\
\text { V8 }\end{array}$ & $\begin{array}{l}\text { pyoderma gangrenosum } \\
\text { From a case of bovine mastitis (BB strain) } \\
\text { From a pyogenic infection (Gladstone and van Heyningen, } \\
\text { 1957); a classical leucocidin-producing strain. }\end{array}$ \\
\hline
\end{tabular}

* The SM series of staphylococcal strains is held by the Department of Bacteriology, Royal Infirmary, Glasgow (see McKay, 1975).

mixtures of these substances with opposing actions. Investigations of the effects of staphylococci on leucocytes must therefore include studies of the activity of purified bacterial products.

In this paper we report a thorough study of the effects on leucocyte locomotion of staphylococci and staphylococcal products. We tested the chemotactic and inhibitory activities of whole cells, extracts from whole cells, culture supernates, fractions of culture supernates prepared by isoelectric focusing and highly purified staphylococcal toxins. Since there has been no study of the effects of staphylococci on migration of monocytes or macrophages, we have studied the migration of both human blood neutrophils and blood monocytes.

\section{MATERIAL AND METHODS}

Strains. The origins of the nine strains of Staphylococcus aureus used in this study are shown in table I. Strains numbered SM1, 6, 9, 10, 14 and 15 were maintained at $-196^{\circ} \mathrm{C}$ in liquid nitrogen in a Vivostat (BOC Cryoproducts) whilst nos. SM2, SM3 and V8 were stored as freeze-dried cultures.

\section{Screening tests for toxins and enzymes}

Toxin and enzyme patterns of the staphylococcal strains used in this study are shown in table II.

Haemolysin production. With the exception of strain V8, each strain was grown on semisolid nutrient agar in an atmosphere of $20 \%(\mathrm{v} / \mathrm{v}) \mathrm{CO}_{2}$ at $37^{\circ} \mathrm{C}$ for $48 \mathrm{~h}$ (Lominski and Arbuthnott, 1962). These cultures were frozen and thawed, and then centrifuged at $800 \mathrm{~g}$ for 10 min. The culture supernates obtained in this way were assayed for haemolytic activity according to the method of Arbuthnott et al. (1969).

Leucocidin production. Strains were grown in a casein hydrolysate-yeast diffusate medium (CCY; Gladstone and van Heyningen, 1957). The only modification was the source of casamino acids which was Difco and of yeast extract which was Oxoid. Organisms were 
TABLE II

Toxin and enzyme patterns of the staphylococcal strains

\begin{tabular}{|c|c|c|c|c|c|c|c|}
\hline \multirow{2}{*}{$\begin{array}{l}\text { Strain } \\
\text { no. }\end{array}$} & \multicolumn{6}{|c|}{ Production of } & \multirow{2}{*}{$\begin{array}{l}\text { Principal } \\
\text { toxin or } \\
\text { toxins } \\
\text { produced }\end{array}$} \\
\hline & coagulase & DNAase & $\begin{array}{l}\text { tribut- } \\
\text { yrinase }\end{array}$ & $\begin{array}{c}\text { fibrino- } \\
\text { lysin }\end{array}$ & $\begin{array}{l}\text { gelatin- } \\
\text { ase }\end{array}$ & $\begin{array}{l}\text { egg-yolk } \\
\text { factor }\end{array}$ & \\
\hline SM1 & + & + & + & + & + & + & $\alpha$ \\
\hline SM2 & + & + & + & + & - & + & $\alpha,(\beta)$ \\
\hline SM3 & + & + & + & - & - & - & $\alpha,(\beta)$ \\
\hline SM6 & $\overline{+}$ & $\overline{1}$ & $(+)$ & - & $(+)$ & - & - \\
\hline $\begin{array}{l}\text { SM9 } \\
\text { SM10 }\end{array}$ & \pm & $i$ & \pm & $\bar{t}$ & 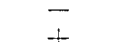 & \pm & $(\alpha) \beta$ \\
\hline $\begin{array}{l}\text { SM10 } \\
\text { SM14 }\end{array}$ & $\begin{array}{l}+ \\
+\end{array}$ & $\begin{array}{l}t \\
t\end{array}$ & $\dot{t}$ & + & $t$ & \pm & $\begin{array}{l}\alpha, \beta \\
\alpha, \beta\end{array}$ \\
\hline SM15 & + & + & + & - & + & + & $(\alpha), \beta$ \\
\hline V8 & + & $\ldots$ & + & $\ldots$ & + & $\ldots$ & leucocidin \\
\hline
\end{tabular}

cultured for $20 \mathrm{~h}$ at $37^{\circ} \mathrm{C}$ in an orbital incubator ( 100 cycles per min.), harvested by centrifugation at $8000 \mathrm{~g}$ for $10 \mathrm{~min}$. and the culture supernates assayed for leucocidin activity (Gladstone et al., 1962).

Enzymes. Production of coagulase, fibrinolysin, gelatinase, lipase and egg-yolk factor by the strains was measured by the method of Arbuthnott et al. (1969). DNAase production was assessed by streaking the strains on DNase Test Agar (Difco), incubating this for $24 \mathrm{~h}$ at $37^{\circ} \mathrm{C}$ and then flooding the plate with $10 \%(\mathrm{w} / \mathrm{v})$ perchloric acid; clearing around the streaks was recorded as a positive result.

\section{Purification and extraction procedures}

Isoelectric focusing (IEF). The method of McNiven, Owen and Arbuthnott (1972) was used with the modification that carrier ampholytes (LKB Ampholine) of the $p \mathrm{H}$ range $3 \cdot 5-10 \cdot 0$ and $9 \cdot 0-11 \cdot 0$ were added in the ratio $5: 1(\mathrm{w} / \mathrm{v})$. The final concentration of Ampholine was $1 \%(\mathrm{w} / \mathrm{v})$.

Culture supernate containing $\alpha$ toxin from $S$. aureus strain Wood 46 (no. NCTC7121) was produced and prepared for isoelectric focusing as described by McNiven et al. (1972). Protein content of the toxin sample before electrofocusing was estimated by the method of Lowry et al. (1951) with crystalline bovine albumin (BSA; Sigma, type F) as standard. Protein content of fractions from the IEF profile was monitored as $\mathrm{E}_{280}^{1 \mathrm{~cm}}$ with a Pye Unicam SP1800 spectrophotometer. Before assay for chemotactic activity, Ampholine was removed from the fractions by dialysis against $0.03 \mathrm{M}$ sodium-borate buffer at $p \mathrm{H} 8 \cdot 3$. Haemolytic activity of fractions against rabbit RBC was measured as described by McNiven et al. (1972). Activity against sheep RBC was determined as follows: sheep RBC washed three times with physiological saline were suspended at $0.7 \%(\mathrm{w} / \mathrm{v})$ in $0.01 \mathrm{M}$ Tris buffer $p \mathrm{H} 7.4$ containing $0.15 \mathrm{M} \mathrm{NaCl}$ and $0.01 \mathrm{M} \mathrm{MgCl}$. This buffer was used throughout in titrations against sheep RBC. Titrations were carried out as described for rabbit RBC but, after incubation for 30 min. at $37^{\circ} \mathrm{C}$ the cells were incubated for a further $60 \mathrm{~min}$. at $4^{\circ} \mathrm{C}$ to obtain an estimate of " hot-cold" haemolytic activity.

Staphylococcal $\alpha$ toxin. Highly purified $\alpha$ toxin was prepared from $S$. aureus strain Wood 46. Preliminary purification by ammonium-sulphate precipitation and preparative IEF was carried out as described by McNiven et al. (1972). The main $\alpha$ toxin component $\left(\alpha_{a}, p I\right.$ $8 \cdot 55 \pm 0 \cdot 12)$ was then refocused under identical conditions on the LKB 8101 (110-ml) column.

J. MED. MICROBIOL.-VOL. 9 (1976) 
The peak active fraction obtained on refocusing was dialysed against $85 \%(w / v)$ saturated ammonium sulphate at $p \mathrm{H} \mathrm{7.0}$ to concentrate the protein and remove Ampholine. The fine precipitate was harvested by centrifugation at $39000 \mathrm{~g}$ for $20 \mathrm{~min}$. and was redissolved in $0.03 \mathrm{M}$ sodium-borate buffer, $p \mathrm{H} 8 \cdot 3$.

Purity of the toxin was assessed by several criteria: (a) a single precipitin line was formed in double diffusion tests against commercial $\alpha$ antitoxin (Wellcome Research Laboratories, Beckenham, Kent); (b) sodium dodecyl sulphate (SDS)-polyacrylamide gel electrophoresis showed the toxin to contain a major component (mol. wt. 36000$)$ and trace material having an approximate mol. wt. of 170000 (McNiven et al., 1972); and (c) there was no detectable contamination with staphylococcal lipase (tributyrinase), egg-yolk factor, fibrinolysin coagulase, phosphatase, gelatinase, $\beta$ toxin, $\delta$ toxin or leucocidin.

Staphylococcal $\beta$ toxin (sphingomyelinase C). Partially purified staphylococcal $\beta$ toxin prepared from $S$. aureus strain no. CN6547 by Dr C. M. Thorley was kindly supplied as an "ammonium-sulphate slurry" by Wellcome Research Laboratories, Beckenham, Kent.

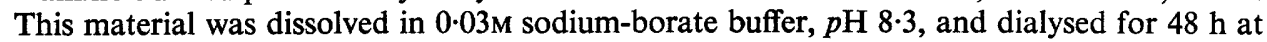
$4^{\circ} \mathrm{C}$ against the same buffer to remove residual ammonium sulphate. After dialysis against $1 \%(\mathrm{w} / \mathrm{v})$ glycine this material was purified by IEF by the modified method of McNiven et al. (1972). The peak fraction of $\beta$ toxin activity ( $p$ I 9.28 \pm 0.09 ; McCartney and Arbuthnott, to be published) so obtained was then refocused under the same conditions on the LKB 110-ml column. After refocusing, the toxin was dialysed against $0.03 \mathrm{M}$ sodium-borate buffer at $p \mathrm{H}$ 8.3 to remove Ampholine. The highly purified $\beta$ toxin obtained exhibited both the "hotcold " haemolytic activity against sheep RBC and the sphingomyelinase activity characteristic of $\beta$ toxin (Doery et al., 1965). SDS-polyacrylamide gel electrophoresis showed the toxin to contain a main band (mol. wt. 29 500) and also a minor band (mol. wt. 16500 ; McCartney and Arbuthnott, to be published). The minor band was identified as staphylococcal DNAase. There was no detectable fibrinolysin, lipase (tributyrinase), gelatinase, phosphatase or eggyolk factor in the purified toxin.

Lipid extraction of the organisms. Lipid extractions were performed on washed organisms by the method of Bligh and Dyer (1959) which yielded a chloroform phase and a methanolwater phase. These fractions were brought to dryness either by rotary evaporation under partial vacuum or by lyophilisation.

Infrared spectroscopy. Samples of material for infrared spectroscopic examination were made anhydrous and were incorporated into potassium bromide disks. Spectra from $4000 \mathrm{~cm}^{-1}$ to $750 \mathrm{~cm}^{-1}$ were read on a Perkin-Elmer Model 237 grating infrared spectrophotometer.

\section{Chemotaxis procedures}

Source and separation of blood leucocytes. In all experiments, human blood leucocytes were used. Human venous blood was collected into bottles containing preservative-free heparin (Evans Medical). After gently mixing, the RBC were sedimented for $1 \mathrm{~h}$ by adding Dextraven $110(6 \% \mathrm{w} / \mathrm{v})$ to the blood in the ratio $1: 9(\mathrm{v} / \mathrm{v})$. The supernatant plasma was layered on to Ficoll-Triosil (SG 1.078; Pharmacia, Uppsala and Nyegard, Oslo) and was spun at $500 \mathrm{~g}$ for $30 \mathrm{~min}$. The mononuclear cell layer and the granulocyte layer were taken separately and washed gently in Gey's solution (Wilkinson, 1974) and then made up to a concentration of $10^{6}$ cells per $\mathrm{ml}$ in Gey's solution for use in chemotaxis tests.

Assay for direct chemotactic effect on leucocytes. The modified Boyden chamber system of Zigmond and Hirsch (1973) was used, in which leucocytes were allowed to migrate from an upper chamber into a micropore filter. The filter pore size was $12 \mu \mathrm{m}$ (Sartorius, Göttingen, Germany) for monocyte migration and $3 \mu \mathrm{m}$ (Millipore, Bedford, Massachussets, USA) for neutrophil migration. The test substance was placed in a lower chamber so that it diffused upwards to form a concentration gradient. The tests were incubated for a specified period of time ( $2 \mathrm{~h}$ for monocytes and $75 \mathrm{~min}$. for neutrophils). The test substance and the test leucocytes were suspended in Gey's solution. Chemotactic activity of a substance was determined by measuring the distance $(\mu \mathrm{m})$ travelled by the leading front of moving cells from the upper surface of the filter towards that substance in a specified time (Zigmond and 
TABLE III

Comparative haemolytic titres of culture supernates from semisolid agar (SSA) and CCY medium*

\begin{tabular}{|c|c|c|c|c|c|c|c|c|}
\hline \multirow{3}{*}{$\begin{array}{l}\text { Strain } \\
\text { no. }\end{array}$} & \multirow{2}{*}{\multicolumn{2}{|c|}{$\begin{array}{l}\text { Titre against } \\
\text { rabbit RBC with } \\
\text { preparations } \\
\text { from }\end{array}$}} & \multirow{2}{*}{\multicolumn{2}{|c|}{$\begin{array}{l}\text { Titre against } \\
\text { human RBC with } \\
\text { preparations } \\
\text { from }\end{array}$}} & \multicolumn{4}{|c|}{$\begin{array}{l}\text { Titre against sheep } \mathbf{R B C} \text { with } \\
\text { preparations from }\end{array}$} \\
\hline & & & & & \multicolumn{2}{|c|}{ SSA at } & \multicolumn{2}{|c|}{$\mathrm{CCY}$ at } \\
\hline & SSA & $\mathrm{CCY}$ & SSA & $\mathrm{CCY}$ & $37^{\circ} \mathrm{C}$ & $4^{\circ} \mathrm{C}$ & $37^{\circ} \mathrm{C}$ & $4^{\circ} \mathrm{C}$ \\
\hline $\begin{array}{l}\text { SM1 } \\
\text { SM2 } \\
\text { SM3 } \\
\text { SM6 } \\
\text { SM9 } \\
\text { SM10 } \\
\text { SM14 } \\
\text { SM15 } \\
\text { V8 }\end{array}$ & $\begin{array}{r}5000 \\
128 \\
64 \\
10 \\
80 \\
1280 \\
640 \\
1280 \\
\ldots\end{array}$ & $\begin{array}{r}16 \\
2 \\
2 \\
2 \\
32 \\
64 \\
32 \\
32 \\
32\end{array}$ & $\begin{array}{l}40 \\
16 \\
32 \\
10 \\
80 \\
80 \\
80 \\
80 \\
\ldots\end{array}$ & $\begin{array}{l}4 \\
4 \\
2 \\
4 \\
2 \\
2 \\
8 \\
8 \\
2\end{array}$ & $\begin{array}{r}160 \\
32 \\
16 \\
10 \\
80 \\
320 \\
160 \\
1280 \\
\ldots\end{array}$ & $\begin{array}{r}320 \\
128 \\
64 \\
10 \\
160 \\
640 \\
320 \\
20000 \\
\ldots\end{array}$ & $\begin{array}{r}2 \\
4 \\
16 \\
2 \\
16 \\
32 \\
8 \\
32 \\
32\end{array}$ & $\begin{array}{r}8 \\
16 \\
32 \\
2 \\
32 \\
32 \\
16 \\
32 \\
64\end{array}$ \\
\hline
\end{tabular}

Hirsch, 1973); a microscope with a calibrated fine-focusing adjustment was used. Tests were done in duplicate, and the results given in the tables are means of five readings from each of two filters. Positive and negative control tests were performed in quadruplicate. Negative control chambers contained Gey's solution only and positive controls contained casein (Merck, Darmstadt, Germany) $1 \mathrm{mg}$ per ml in Gey's solution. Staphylococci were washed twice in physiological saline before being resuspended in Gey's solution at concentrations of $10^{6}$ organisms per $\mathrm{ml}$ for testing.

Assay for inhibition of leucocyte locomotion. This assay was as described above with the modification that a standard chemotactic stimulus (casein $1 \mathrm{mg} \mathrm{per} \mathrm{ml}$ ) was added to all of the lower test chambers and fractions obtained by IEF or purified toxins were also added to individual chambers. The inhibitory activity present in a test staphylococcal fraction was assessed by determining the distance migrated towards casein in the presence of the test fraction and comparing the distance of migration towards casein in the absence of the fraction.

Assay for cytotaxigenic (serum-dependent) effect of staphylococcal products on leucocytes. This was done in the same way as the direct chemotactic assay, but serum complement (normal human serum, $10 \%$ ) was added to each test chamber containing staphylococcal fractions and to the negative controls lacking staphylococcal fractions. On incubation of the test chambers at $37^{\circ} \mathrm{C}$, complement-fixing or other activating factors derived from the organisms are assumed to interact with the serum and release chemotactic factors that would attract the cells above the filter.

\section{Storage and use of toxins}

After preparation and titration, the purified toxins were diluted 20-fold with Gey's solution; small portions were stored at $-70^{\circ} \mathrm{C}$. These were thawed for use and then discarded as they were unstable. In use, toxins were added to leucocytes at the final dilutions shown in table VIII and the leucocyte-toxin mixture was added immediately to the upper compartment of a chemotaxis chamber. The same concentration of toxin was also added to the lower compartment of the chamber so that the toxin concentration was constant throughout the system, thus avoiding gradient formation. Tests were then incubated at $37^{\circ} \mathrm{C}$ as described above. 


\section{TABLE IV}

Direct chemotactic activity of washed staphylococcal organisms for human leucocytes at $10^{6}$ organisms per $\mathrm{ml}$

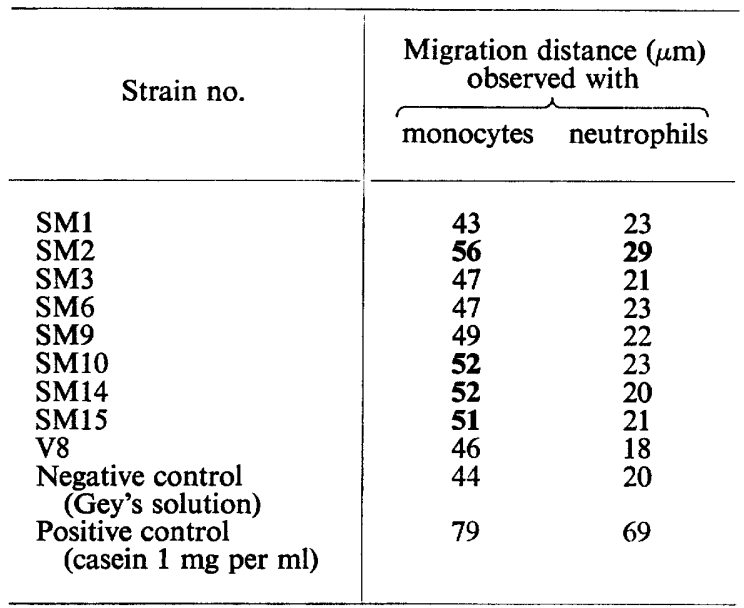

Bold type denotes increased migration in comparison with negative control.

\section{ResulTs}

Table III compares the haemolytic activities of the strains grown $(a)$ in semi-solid agar (SSA), under conditions favouring leucocidin production, and (b) in CCY medium which favours production of other toxins. Titres of haemolysins active against rabbit and human RBC denote levels of $\alpha$ - and $\gamma$ - or $\delta$-haemolytic activity respectively, whilst the hot-cold lytic effect against sheep $\mathrm{RBC}$ is characteristic of $\beta$ toxin.

\section{Direct chemotactic activity of washed intact staphylococci}

Suspensions of washed organisms $\left(10^{6}\right.$ per $\left.\mathrm{ml}\right)$ from nine strains of $S$. aureus were tested for direct chemotactic activity (see table IV). Only one of the nine strains (SM2) showed any chemotactic activity for neutrophils, whereas four of the strains showed activity for monocytes at this concentration, strain SM2 being most active.

\section{Direct chemotactic activity of culture supernates}

Culture supernates of the nine different strains grown for $18 \mathrm{~h}$ in CCY medium were tested immediately after preparation for direct chemotactic effect on both monocytes and neutrophils at the dilutions indicated in table V. Eight supernates enhanced locomotion of monocytes at dilutions of 1 in 1000, 
TABLE V

Direct chemotactic activity of staphylococcal culture filtrates for human leucocytes

\begin{tabular}{|c|c|c|c|c|c|c|c|c|c|c|c|c|}
\hline \multirow{2}{*}{$\begin{array}{c}\text { Strain } \\
\text { no. }\end{array}$} & \multicolumn{6}{|c|}{$\begin{array}{l}\text { Migration distance of monocytes }(\mu \mathrm{m}) \\
\text { towards culture filtrate at a dilution of } 1 \text { in }\end{array}$} & \multicolumn{6}{|c|}{$\begin{array}{l}\text { Migration distance of neutrophils }(\mu \mathrm{m}) \\
\text { towards culture filtrate at a dilution of } 1 \text { in }\end{array}$} \\
\hline & 100 & 1000 & 5000 & 10000 & 50000 & 100000 & 100 & 1000 & 5000 & 10000 & 50000 & 100000 \\
\hline $\begin{array}{l}\text { SM1 } \\
\text { SM2 } \\
\text { SM3 } \\
\text { SM6 } \\
\text { SM9 } \\
\text { SM10 } \\
\text { SM14 } \\
\text { SM15 } \\
\text { V8 }\end{array}$ & $\begin{array}{l}36 \\
49 \\
91 \\
74 \\
78 \\
55 \\
34 \\
\mathbf{6 8} \\
22\end{array}$ & $\begin{array}{l}74 \\
53 \\
46 \\
61 \\
72 \\
55 \\
45 \\
56 \\
42\end{array}$ & $\begin{array}{l}36 \\
36 \\
36 \\
36 \\
32 \\
36 \\
32 \\
36 \\
39\end{array}$ & $\begin{array}{l}36 \\
37 \\
36 \\
32 \\
36 \\
36 \\
36 \\
36 \\
36\end{array}$ & $\begin{array}{l}\ldots \\
\cdots \\
\cdots \\
\cdots \\
\cdots \\
\cdots \\
\dddot{36}\end{array}$ & $\begin{array}{l}\ldots \\
\ldots \\
\ldots \\
\ldots \\
\cdots \\
\ldots \\
36\end{array}$ & $\begin{array}{r}34 \\
30 \\
35 \\
.35 \\
35 \\
27 \\
36 \\
40 \\
0\end{array}$ & $\begin{array}{l}30 \\
34 \\
35 \\
35 \\
35 \\
40 \\
35 \\
35 \\
34\end{array}$ & $\begin{array}{l}35 \\
35 \\
35 \\
35 \\
34 \\
34 \\
35 \\
33 \\
42\end{array}$ & $\begin{array}{l}35 \\
35 \\
35 \\
34 \\
32 \\
34 \\
28 \\
33 \\
37\end{array}$ & $\begin{array}{l}\ldots \\
\ldots \\
\cdots \\
\ldots \\
\ldots \\
\cdots \\
\ldots \\
32\end{array}$ & $\begin{array}{l}\ldots \\
\cdots \\
\cdots \\
\cdots \\
\cdots \\
\cdots \\
\cdots \\
\ldots \\
33\end{array}$ \\
\hline $\begin{array}{l}\text { Unused } \\
\text { culture } \\
\text { medium }\end{array}$ & 35 & 32 & $\ldots$ & $\ldots$ & $\cdots$ & $\cdots$ & 37 & 30 & $\ldots$ & $\ldots$ & $\ldots$ & $\ldots$ \\
\hline $\begin{array}{c}\text { Negative } \\
\text { control }\end{array}$ & 36 & $\ldots$ & $\ldots$ & $\ldots$ & $\ldots$ & $\ldots$ & 35 & $\ldots$ & $\cdots$ & $\ldots$ & $\ldots$ & $\ldots$ \\
\hline $\begin{array}{l}\text { Positive } \\
\text { control }\end{array}$ & 78 & $\ldots$ & $\ldots$ & $\cdots$ & $\cdots$ & $\cdots$ & 143 & $\ldots$ & $\cdots$ & $\cdots$ & $\cdots$ & $\cdots$ \\
\hline
\end{tabular}

$\ldots=$ Not tested.

Bold type denotes increased migration in comparison with negative control.

whereas none showed activity for neutrophils at this dilution. Sterile CCY culture medium gave a low background chemotactic activity which was not detectable at dilutions of 1 in 100 or more.

\section{Inhibition of leucocyte locomotion by culture supernates}

Samples of the same culture supernates tested for direct chemotactic activity were assayed for inhibitory effects on cells moving towards a standard chemotactic stimulus. Seven of the nine supernates contained inhibitors of neutrophil locomotion active at a dilution of 1 in 10000 or more (see table VI). Three of these supernates still exerted marked inhibitory activity at a dilution of 1 in 50000 . Out of nine supernates, only one (strain SM14) was almost totally inactive in inhibiting neutrophil locomotion. In contrast, inhibition of monocyte locomotion was seen with only three of the nine supernates at a dilution of 1 in 10000 , whilst at a dilution of 1 in 50000 no supernate had monocyte-inhibitory activity. Three of the supernates were non-inhibitory for monocyte locomotion at all dilutions tested above 1 in 100 . The supernate from the V8 strain was remarkable for the potency of its inhibitory activity for neutrophils which was demonstrable up to a dilution of 1 in 200000 ; this was 20 times more potent than its inhibitory effect on monocyte locomotion which was not demonstrable with dilutions above 1 in 10000 . It was concluded that staphylococcal supernates contain inhibitors of locomotion of both 
TABLE VI

Inhibition of human-leucocyte locomotion towards a standard chemotactic stimulus by staphylococcal culture filtrates

\begin{tabular}{|c|c|c|c|c|c|c|c|c|c|c|c|c|c|c|c|c|}
\hline \multirow{2}{*}{$\begin{array}{c}\text { Strain } \\
\text { no. }\end{array}$} & \multicolumn{7}{|c|}{$\begin{array}{l}\text { Migration distance of monocytes }(\mu \mathrm{m}) \text { towards the } \\
\text { culture filtrate at a dilution of } 1 \text { in }\end{array}$} & \multicolumn{9}{|c|}{$\begin{array}{l}\text { Migration distance of neutrophils }(\mu \mathrm{m}) \text { towards the culture filtrate } \\
\text { at a dilution of } 1 \text { in }\end{array}$} \\
\hline & 100 & 500 & 1000 & 15000 & 10000 & 25000 & 50000 & 100 & 500 & 1000 & 5000 & 10000 & 25000 & 50000 & 100000 & 200000 \\
\hline SM1 & 0 & 0 & 0 & 80 & 81 & 82 & 95 & 0 & o & 0 & 59 & 59 & 73 & 74 & $\ldots$ & $\ldots$ \\
\hline SM2 & 105 & 101 & 105 & 103 & 102 & 100 & 102 & o & o & o & 51 & 53 & 48 & 49 & $\ldots$ & $\ldots$ \\
\hline SM3 & 71 & 105 & 105 & 103 & 100 & 101 & 100 & 0 & 0 & 0 & 45 & 56 & 67 & 66 & $\ldots$ & $\ldots$ \\
\hline SM6 & 0 & 0 & 0 & 72 & 102 & 101 & 102 & 0 & o & 0 & 32 & 36 & 36 & 47 & $\ldots$ & $\ldots$ \\
\hline SM9 & $\mathbf{0}$ & 0 & 0 & 75 & 81 & 104 & 101 & 0 & 0 & 0 & 31 & 34 & 39 & 71 & $\ldots$ & $\ldots$ \\
\hline SM10 & 83 & 106 & 106 & 107 & 100 & 101 & 103 & 0 & 0 & 0 & 59 & 61 & 59 & 73 & $\ldots$ & $\ldots$ \\
\hline SM14 & 0 & 0 & 0 & 70 & 98 & 104 & 104 & 26 & 57 & 77 & 70 & 69 & 70 & 70 & $\ldots$ & $\ldots$ \\
\hline SM15 & 0 & 0 & 0 & 68 & 100 & 100 & 101 & 0 & 0 & 0 & 49 & 72 & 69 & 70 & $\ldots$ & $\ldots$ \\
\hline V8 & 0 & 0 & 0 & 0 & 88 & 112 & 100 & 0 & 0 & 0 & 36 & 38 & 40 & 47 & 55 & 66 \\
\hline
\end{tabular}

$\ldots=$ Not tested.

Bold type denotes decreased migration in comparison with positive controls; $103 \mu \mathrm{m}$ for monocyte migration and $73 \mu \mathrm{m}$ for neutrophil migration.

monocytes and neutrophils, but that inhibition of neutrophil locomotion is more pronounced than inhibition of monocyte locomotion.

\section{Effects of fractions from a staphylococcal culture supernate on leucocyte locomotion}

One strain, S. aureus no. SM1 (Wood 46), was selected from the nine for more detailed investigation. IEF fractions prepared from the culture supernate of this strain were tested for direct chemotactic activity at three dilutions, 1 in 1000, 10000 and 100000 and for inhibitory activity at one dilution, 1 in 1000. Since 64 fractions were each tested for chemotactic activity at three dilutions and for inhibitory activity at a single dilution the results of these experiments have of necessity been greatly condensed for publication. Chemotactic or inhibitory activity of each fraction along the $p \mathrm{H}$ range has thus been arbitarily scored 0 to +++ for strength of activity, each + representing a $10-\mu \mathrm{m}$ difference in migration from the control value. It is not possible to use absolute units as intra-experimental comparisons are invalidated by variation between control values obtained on different days. These experiments showed monocyte-chemotactic activity to be spread over a wide $p \mathrm{H}$ range with peaks occurring at $p \mathrm{H} 4 \cdot 1,4 \cdot 8,5 \cdot 6$ to $5 \cdot 85,6 \cdot 9,7 \cdot 1$ to $7 \cdot 25,7 \cdot 4,7 \cdot 5$ to $7 \cdot 55,7 \cdot 8$ to $7 \cdot 9$, $8 \cdot 15$, and 9.5 to 9.7 (see fig. 1). In contrast, however, direct chemotactic activity for neutrophils was found in only a few fractions and was quite feeble when it did occur (fig. 2). The strongest activity occurred at $p \mathrm{H} 5 \cdot 1$ and 5.6 whilst five peaks of trace activity were scattered between $p \mathrm{H} 5.0$ and 9.5. Inhibition of monocyte locomotion was found in a few distinct peaks at $p \mathrm{H}$ $4 \cdot 1,4 \cdot 6,8.4$ and 9.0 , that at $p \mathrm{H} 8.4$ being most active (fig. 1) whilst there was marked inhibition of neutrophil locomotion over a wide $p \mathrm{H}$ range with strong 


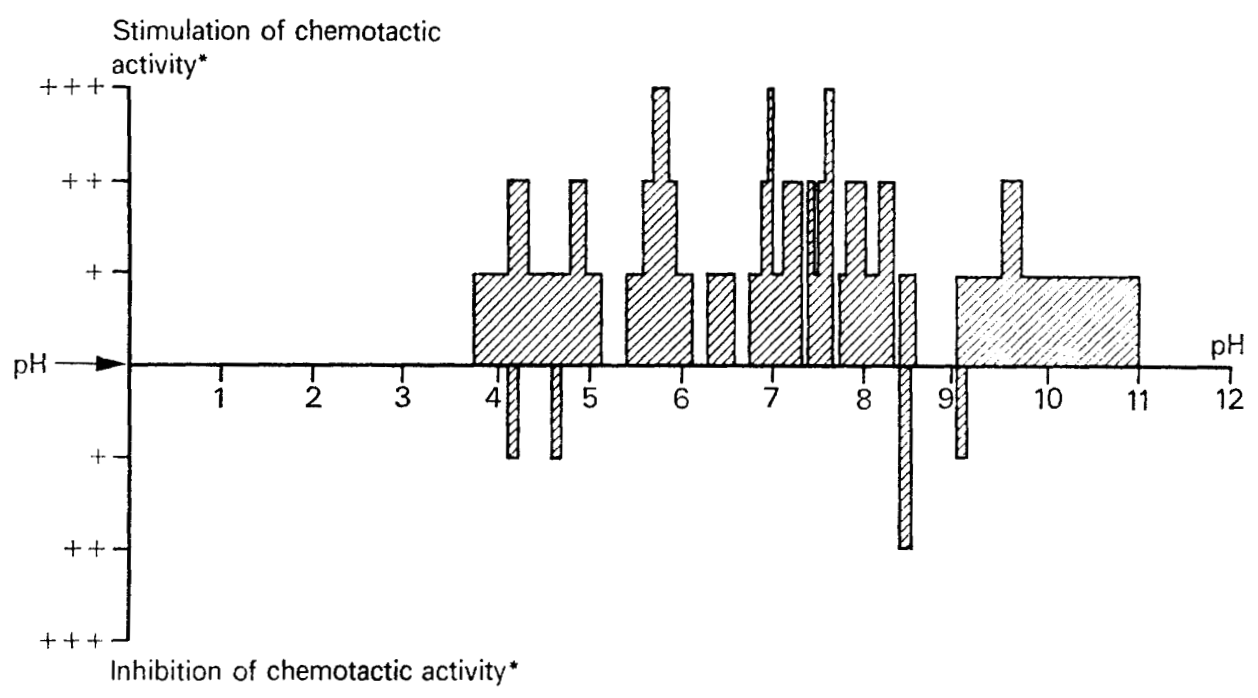

Fig. 1.-Effects of isoelectric-focusing fractions from Staphylococcus aureus strain Wood 46 supernate on locomotion of human blood monocytes. * Each + represents a $10 \mu \mathrm{m}$ difference in migration of the test leucocytes from that of the control.

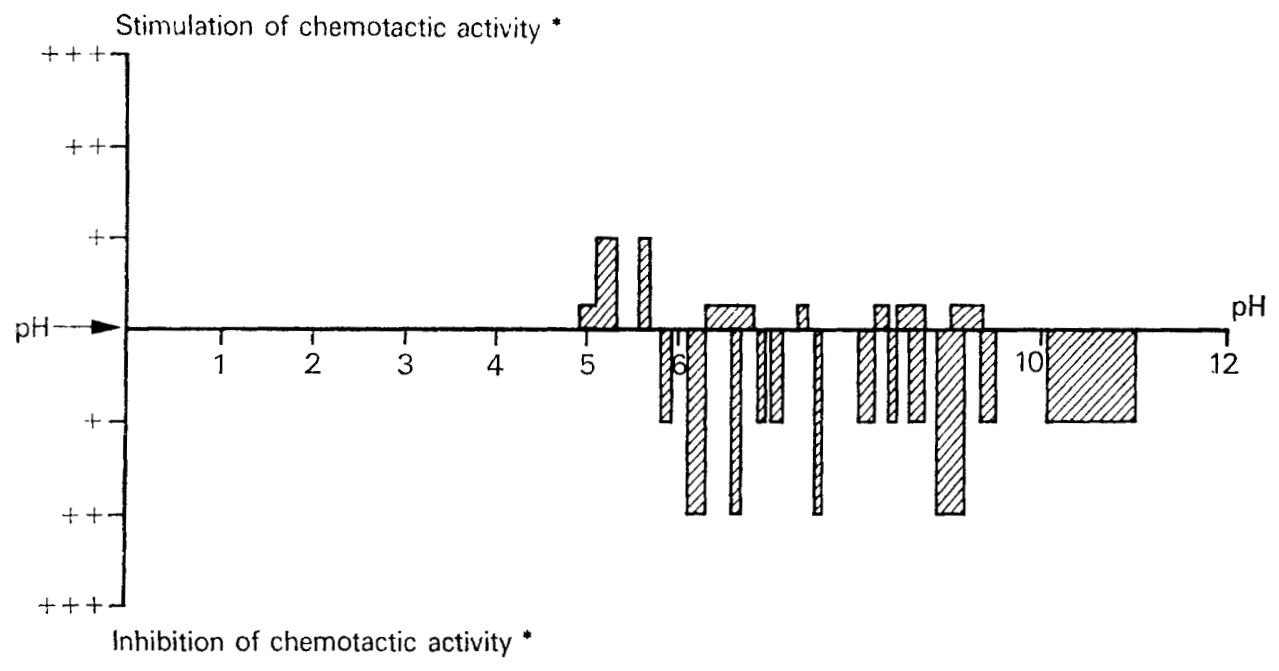

FiG. 2.-Effects of isoelectric-focusing fractions from Staphylococcus aureus strain Wood 46 supernate on locomotion of human blood neutrophils. * See legend to fig. 1. 
peaks at $p \mathrm{H} 6 \cdot 1,6 \cdot 6,7 \cdot 5$, and $8 \cdot 85$ to $9 \cdot 15$ (see fig. 2). IEF fractions of supernates from strain V8, a well-known producer of leucocidin (Gladstone and van Heynigen, 1957) showed patterns of chemotactic activity and inhibition of locomotion similar to those seen with the Wood 46 strain. Direct chemotactic activity for monocytes was widespread across the isoelectric focusing profile yet there was little activity for neutrophils. Inhibition of neutrophil locomotion occurred throughout and was maximal at $p \mathrm{H} 8 \cdot 8$ to $9 \cdot 0$. Inhibition of monocyte locomotion was less marked and was localised mainly in the fraction at $p \mathrm{H} 8.8$ to $9 \cdot 0$. This fraction inhibited neutrophil locomotion at dilutions of up to 1 in 5000, but weak monocyte migration was observed at a 1 in 100 dilution of the fraction.

\section{Nature of directly acting chemotactic factors from $S$. aureus}

The pattern and type of direct chemotactic activity of IEF fractions for monocytes was reminiscent of that seen previously whilst testing various lipid extracts from anaerobic coryneform bacteria (Russell et al., 1975): weak chemotactic activity was distributed among many fractions and there were no clear peaks of significant activity.

Chemotactic effect of fractions prepared by isoelectric focusing from straphylococcal culture supernate incubated in the presence of serum

Neutrophils accumulate in great numbers in staphylococcal lesions in vivo, yet the predominant direct effect of the unfractionated staphylococcal supernates and of IEF fractions derived from them on neutrophil locomotion was inhibitory rather than stimulatory in the tests described above. Previous unpublished experiments in our laboratory had frequently shown that when the Oxford strain of $S$. aureus was incubated with serum at $37^{\circ} \mathrm{C}$, it generated strong neutrophil chemotactic activity. The Wood 46 strain tested for chemotactic effect on neutrophils at $10^{6}$ organisms per $\mathrm{ml}$ in the presence of normal human serum showed the same effect. When incubated with normal human serum pre-heated at $56^{\circ} \mathrm{C}$ to inactivate complement, this effect decreased. To study this phenomenon further, IEF fractions from staphylococcal culture supernates were assayed for cytotaxigenic activity. This was done by including fresh normal human serum in the test chambers along with each test fraction, thus measuring chemotactic activity generated from serum. Each fraction was tested at a dilution of 1 in 1000 . The fractions generated chemotactic activity for neutrophils in the serum and the activity was spread over a wide $p \mathrm{H}$ range with six strong peaks at $p \mathrm{H}$ values of $3 \cdot 0,4 \cdot 1,6 \cdot 45,7 \cdot 55,9 \cdot 5$ and $11 \cdot 0$ (see fig. 3 ). These results suggest that the chemotactic response of neutrophils to staphylococcal infection and products in vivo is chiefly mediated by serum complement or through other enzyme systems in serum, and that attraction of neutrophils by directly acting chemotacic factors released from staphylococci is probably trivial. 


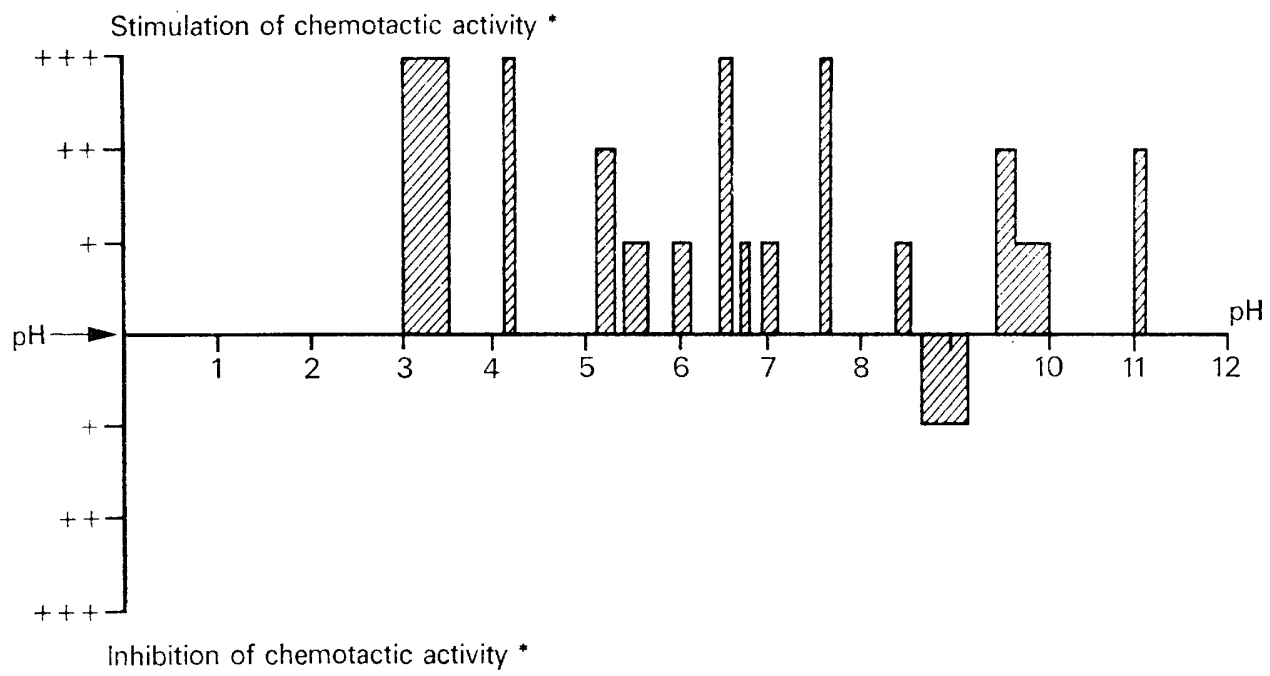

FiG. 3.-Cytotaxigenic effects of isoelectric-focusing fractions from Staphylococcus aureus strain Wood 46 supernate incubated in the presence of normal human serum. * See legend to fig. 1.

We had found that the chemotactic effect of anerobic coryneform bacteria could be partly attributed to pure lipid materials, and we therefore tested lipid fractions from staphylococci for similar effects. IEF fractions of culture supernates of $S$. aureus strain Wood 46 that showed direct chemotactic activity on monocytes and inhibitory activity on the locomotion of monocytes were pooled separately and lyophilised. Chloroform extracts of these were examined by infrared spectroscopy. The spectra of both the chemotactic and inhibitory samples were superimposable except that small peaks were present at $2920 \mathrm{~cm}^{-1}$ and $2850 \mathrm{~cm}^{-1}$ (characteristic of $\mathrm{CH}_{2}$ groups in lipids) in the spectrum of the chemotactic sample but not the inhibitory sample. This provided strong evidence that lipid material was present in the pooled fractions possessing chemotactic activity but was undetectable in the pooled inhibitory fractions.

A lipid extraction was performed on washed Wood 46 organisms. The resultant chloroform-soluble and methanol-water-soluble fractions were tested for chemotactic activity along with whole organisms before and after extraction (table VII). The chloroform-soluble extract was chemotactic for both monocytes and neutrophils. Chemotactic activity on neutrophils was stronger than that seen in any IEF fraction. The hydrophilic water-methanol phase of the extract was relatively inactive. Chemotactic activity of the whole organisms for both neutrophils and monocytes decreased after extraction of lipid. Infrared spectroscopy of the chloroform-soluble fraction showed it to contain large amounts of carbohydrate in addition to lipid and some peptide. Trypsinisation and re-extraction of this material greatly reduced the content of peptide and to a lesser extent the carbohydrate content also, as visualised by the infrared spectra. Trypsinisation of the chloroform-soluble material caused a loss of 


\section{TABLE VII}

Direct chemotactic activity of staphylococcus Wood 46 strain and its lipid extracts for human blood neutrophils and monocytes

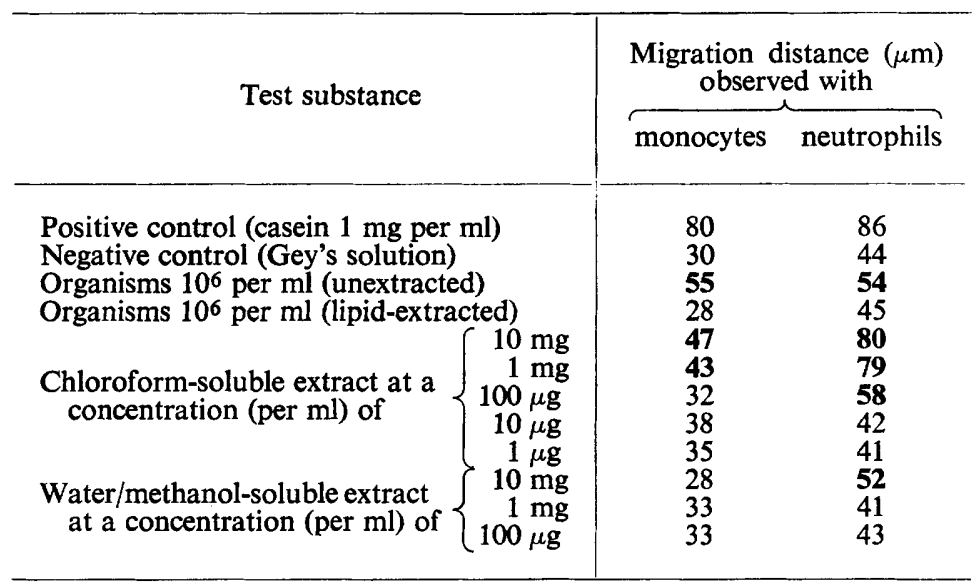

Bold type denotes increased migration in comparison with negative control.

the neutrophil activity though the monocyte activity still remained. This suggests that neutrophil migration is stimulated by lipid associated with protein or peptide and that the activity is reduced or lost when the latter is cleaved by trypsin.

\section{Effect of purified staphylococcal toxins on leucocyte locomotion}

Some of the IEF fractions with the most pronounced inhibition of leucocyte locomotion occurred at points in the $\mathrm{pH}$ gradient at which one would expect known toxic staphylococcal products to focus. Thus, at $p \mathrm{H} 9.0$ a strong inhibitor of neutrophil locomotion and to a lesser extent monocyte locomotion was located. This is the reported position for both leucocidin and $\beta$ toxin (Bernheimer, Avigad and Kim, 1974; Wadström, Thelestam and Möllby, 1974). The main form of $\alpha$ toxin should focus around $p \mathrm{H} 8.5$ (McNiven et al., 1972) and inhibition of both monocyte and neutrophil locomotion was observed in fractions from this region. These observations were extended in studies with highly purified staphylococcal $\alpha$ toxin and $\beta$ toxin: the effects of the toxins on leucocyte locomotion towards a standard chemotactic stimulus were studied at non-toxic doses as judged by observations on (i) the morphology of cells incubated with the toxin, and (ii) Trypan Blue exclusion. Over $90 \%$ of cells appeared viable at all doses of $\beta$ toxin studied, and at doses of $\alpha$ toxin below $200 \mathrm{HU}$ per ml. At a concentration of $200 \mathrm{HU}$ per $\mathrm{ml}$ and above, $\alpha$ toxin had observable toxic effects on monocytes but not on neutrophils. The results are shown in table VIII. Neither toxin showed significant chemotactic activity. However $\alpha$ toxin inhibited the migration of both human monocytes and neutrophils at doses down to $10 \mathrm{HU}$ per $\mathrm{ml}$. It was slightly inhibitory for 
TABLE VIII

Effect of staphylococcal $\alpha$ and $\beta$ toxins on migration of human-blood neutrophils and monocytes

\begin{tabular}{|c|c|c|c|c|}
\hline \multirow{2}{*}{\multicolumn{2}{|c|}{$\begin{array}{l}\text { Amount of toxin } \\
\text { present }\end{array}$}} & \multirow[t]{2}{*}{$\begin{array}{l}\text { Chemotactic factor } \\
\text { below filter }\end{array}$} & \multicolumn{2}{|c|}{$\begin{array}{l}\text { Migration distance (as a per- } \\
\text { centage of positive control } \\
\text { migration to casein) } \\
\text { observed with }\end{array}$} \\
\hline & & & neutrophils & monocytes \\
\hline \multirow{2}{*}{\multicolumn{2}{|c|}{ None }} & None & 20 & 34 \\
\hline & & Casein $800 \mu \mathrm{g}$ per $\mathrm{ml}$ & 100 & 100 \\
\hline \multicolumn{2}{|c|}{$\begin{array}{l}\text { None } \\
\int 200 \mathrm{HU}\end{array}$} & Casein $800 \mu \mathrm{g}$ per $\mathrm{ml}$ & 64 & 34 \\
\hline & $50 \mathrm{HU}$ & Casein $800 \mu \mathrm{g}$ per $\mathrm{ml}$ & 62 & 35 \\
\hline$\alpha$ Toxin & $10 \mathrm{HU}$ & Casein $800 \mu \mathrm{g}$ per $\mathrm{ml}$ & 77 & 51 \\
\hline (per ml) & $2 \mathrm{HU}$ & Casein $800 \mu \mathrm{g}$ per $\mathrm{ml}$ & 101 & 84 \\
\hline & $200 \mathrm{HU}$ & $\begin{array}{l}\text { None } \\
\text { None }\end{array}$ & $\begin{array}{l}22 \\
24\end{array}$ & $\begin{array}{l}31 \\
40\end{array}$ \\
\hline & $10^{4} \mathrm{HU}$ & Casein $800 \mu \mathrm{g}$ per $\mathrm{ml}$ & 89 & 45 \\
\hline & $10^{3} \mathrm{HU}$ & Casein $800 \mu \mathrm{g}$ per ml & 110 & 45 \\
\hline \multirow{4}{*}{$\begin{array}{l}\beta \text { Toxin } \\
\text { (per ml) }\end{array}$} & $10^{2} \mathrm{HU}$ & Casein $800 \mu \mathrm{g}$ per ml & 100 & 66 \\
\hline & $10 \mathrm{HU}$ & Casein $800 \mu \mathrm{g}$ per ml & 103 & 61 \\
\hline & $10^{3} \mathrm{HU}$ & None & 22 & 30 \\
\hline & $10^{2} \mathrm{HU}$ & None & 24 & 32 \\
\hline
\end{tabular}

Bold type denotes decreased migration in comparison with positive control in the presence of casein.

monocytes but not for neutrophils at doses below this. In contrast, as has been reported briefly elsewhere (Wilkinson 1975), $\beta$ toxin had little or no inhibitory effect on neutrophil locomotion. It had a marked inhibitory effect on the locomotion of monocytes towards chemical attractants. The effect of $\beta$ toxin was to inhibit the chemically stimulated locomotion of monocytes, whether or not the chemical stimulant was present in a gradient, but the random unstimulated locomotion of monocytes in the absence of a chemo-attractant was not inhibited by $\beta$ toxin at the doses studied. These results suggest that the integrity of the cell-membrane sphingomyelin is essential for chemically directed locomotion of monocytes but not of neutrophils.

When a mixture of sphingomyelin and $\beta$ toxin were added to the monocytes the inhibitory effect of the $\beta$ toxin was greatly reduced. However, when a mixture of lecithin and $\beta$ toxin was added to monocytes, the inhibitory effect was unaltered; this suggests that the added sphingomyelin, but not the lecithin, was competing as a substrate for sphingomyelinase $\mathrm{C}$ ( $\beta$ toxin) with the sphingomyelin of the cell membrane. This supports the view that $\beta$ toxin exerts the effect by a specific action on sphingomyelin.

\section{DISCUSSION}

We believe that this study of the effects of the staphylococcus on leucocyte locomotion represents the first attempt to examine any pathogenic organism 
as a totality and in detail for such effects, rather than looking at the activity of isolated individual bacterial products. As might be expected, it has revealed a complex pattern of both stimulatory and inhibitory activities. This is in accord with the fact that $S$. aureus produces numerous biologically active metabolites.

In our studies, staphylococcal cells, culture supernates and IEF fractions from culture supernates showed surprisingly little direct chemotactic activity for neutrophils, but a chloroform-soluble fraction from $S$. aureus strain Wood 46 did show this activity. Infrared spectra revealed the presence of carbohydrate and peptide in this extract in addition to lipid. Subsequent trypsinisation reduced the amount of peptide and carbohydrate with simultaneous reduction of the chemotactic activity. These observations suggest that the chemotactic activity could be attributed to a lipoprotein complex. Staphylococci and their fractions also showed indirect chemotactic activity for neutrophils, i.e., they were cytotaxigenic in the presence of plasma. It seems probable that this activity will prove to be due to activation of complement. The activity could not be ascribed to any single staphylococcal product in our IEF studies. Staphylococci and their products did show direct chemotactic activity for blood monocytes. This activity could be detected in many fractions in the IEF profile (fig. 1).

The pattern of inhibitory activity of staphylococcal products on leucocyte locomotion was equally complex. In summary, many fractions were shown to inhibit neutrophil locomotion; fewer fractions inhibited monocyte locomotion. Some of the inhibitory fractions can be identified presumptively. Purified staphylococcal $\alpha$ toxin was shown to inhibit the migration of both neutrophils and monocytes but showed a marginally stronger effect on the latter. As reported previously (Wilkinson, 1975), purified $\beta$ toxin (sphingomyelinase C) prevents human monocytes from migrating towards chemotactic factors but has little or no effect on neutrophil migration. It is of great interest that these toxins showed their effects on cellular locomotion at dose levels at which no cytotoxic effects could be observed. However, the migration inhibition may be due to a membrane-perturbing effect associated with cytotoxicity at higher doses of toxin. $\beta$ Toxin inhibits migration of lymphocytes towards one chemotactic factor (casein) but not towards another (phytohaemagglutinin), and this suggests that the toxin-induced membrane alteration may specifically interfere with the interaction of certain chemotactic factors with the cell membrane (Wilkinson et al., 1976). This may be of considerable importance in understanding the actions of these toxins in the pathogenesis of disease. Moreover, a knowledge of the specificity of certain bacterial toxins for lipid components of cell membranes could help in the elucidation of the role of individual membrane components in cellular functions such as chemotaxis.

The V8 strain of $S$. aureus was more active in inhibiting neutrophil locomotion than any other strain tested and the major peak of inhibitory activity of this focused at $p H 9 \cdot 0$. These findings suggest that the major inhibitor of neutrophil locomotion is leucocidin, although this requires to be confirmed with more highly purified material. It would certainly be consistent with Woodin's 
findings (1971) that leucocidin shows an affinity for the lipids of neutrophil membranes and acts there to inhibit a number of functions including locomotion. It is again of interest that inhibitory effects of the V8 strain on neutrophil locomotion could be detected at concentrations 100 times lower than those at which cytotoxic effects could be observed.

It is not possible at the moment from in-vitro studies of the type reported here to gain a detailed understanding of the effect of individual products on host leucocytes in the genesis of staphylococcal lesions. For instance, we do not know with certainty which cell-associated or excreted factors are produced in vivo by $S$. aureus during host infection and we do not know the amounts that might be produced in vivo. S. aureus strains vary considerably in pathogenicity and toxigenicity, and an understanding of the kinetics of production of such factors in vivo is also of considerable importance. With these limitations in mind, the present study has established that $S$. aureus strains have the potential ability to produce certain factors which are directly or indirectly chemotactic and others which act directly to inhibit chemotaxis. It is possible to envisage that the cytotaxigenic (complement-dependent) factors may exert " long-range" chemotactic effects that attract leucocytes to the focus of staphylococcal infection and that the "short-range" inhibitory activity of other factors such as leucocidin, $\alpha$ toxin and $\beta$ toxin may allow the organism to resist the phagocytic defences of the host to a certain extent. However, the complexity of the possible interactions is again emphasised by the observations of Hill and his co-workers (Weksler and Hill, 1969), who found that mouse-pathogenic strains of $S$. aureus produce a cell-associated mucopeptide-protein complex which exerts an anti-inflammatory effect and inhibits chemotaxis of neutrophils. Much further work is required to characterise the factors produced by different strains of $S$. aureus that stimulate or inhibit leucocyte locomotion.

\section{SUMMARY}

The effects of staphylococcal products as chemo-attractants for human blood neutrophils and monocytes and as inhibitors of locomotion of these cells were studied with bacterial cells, culture filtrates and isoelectrically focused fractions from culture filtrates of nine strains of Staphylococcus aureus. Little direct chemotactic activity of staphylococcal products for neutrophils was observed, although a chloroform-soluble extract of the whole organisms contained such activity. The major chemotactic effect of staphylococci for neutrophils was indirect, i.e., generated when the organisms or their products were incubated with plasma, perhaps due to activation of complement. In contrast, direct chemotactic activity for monocytes was found in a large number of staphylococcal fractions. Staphylococci also produced inhibitors of locomotion of both neutrophils and monocytes. Isoelectric focusing showed more fractions inhibitory for neutrophils than for monocytes. Some of the inhibitors could be identified. Staphylococcal $\alpha$-toxin inhibited migration of both neutrophils and monocytes. Sphingomyelinase $\mathrm{C}$ ( $\beta$ toxin) inhibited migration of monocytes but not of neutrophils. Leucocidin-rich strains were 
strongly active as inhibitors of neutrophil locomotion but less so as inhibitors of monocyte locomotion.

We are indebted to Mrs Bronwen Billcliffe and Mr James Paton for technical assistance. R. J. R. was supported by an MRC scholarship. This is publication no. 7527 of the Department of Bacteriology and Immunology, Western Infirmary, University of Glasgow.

\section{REFERENCES}

Arbuthnott, J. P., Gemmill, C. G., Kent, J. And Lyell, A. 1969. Haemolysin and enzyme patterns of coagulase positive staphylococci isolated from toxic epidermal necrolysis, Ritter's disease and impetigo contagiosa. J. med. Microbiol., 2, 478.

Bernheimer, A. W., Avigad, L. S. AND KIM, K. S. 1974. Staphylococcal sphingomyelinase ( $\beta$-haemolysin). Ann. N.Y. Acad. Sci., 236, 292.

Bligh, E. G. AND DYER, W. J. 1959. A rapid method of total lipid extraction and purification. Can. J. Biochem. Physiol., 37, 911.

Craig, C. P., Normann, S. J., McGann, V. and Irvin, W. S. 1971. Chemotactic activity generated by staphylococcal enterotoxin B. Infect. Immun., 3, 94.

Doery, H. M., Magnusson, B. J., Gulasekharam, J. and Pearson, J. E. 1965. The properties of phospholipase enzymes in staphylococcal toxins. J. gen. Microbiol., 40, 283.

Gladstone, G. P., Mudd, S., Hochstein, H. D. and Lenhart, N. A. 1962. The assay of anti-staphylococcal leucocidal components (F and $\mathrm{S}$ ) in human serum. Br.J. exp. Path., 43, 295.

Gladstone, G. P. and van Heyningen, W. E. 1957. Staphylococcal leucocidins. $B r . J$. exp. Path., 38, 123.

Harvey, R. L., Kronvall, G., Troup, G. M., Anderson, R. E. and Williams, R. C. 1970. Chemotaxis of polymorphonuclear leukocytes by protein $\mathbf{A}$ of the staphylococcus. Proc. Soc. exp. Biol. Med., 135, 453.

Keller, H. U. AND Sorkin, E. 1967. Studies on chemotaxis. V. On chemotactic effect of bacteria. Int. Arch. Allergy appl. Immunol., 31, 505.

Lominski, I. AND ARButhnOTT, J. P. 1962. Some characteristics of staphylococcus alphahaemolysin. J. Path. Bact., 83, 515.

Lowry, O. H., Rosebrough, N. J., FARR, A. L. ANd Randall, R. J. 1951. Protein measurement with the Folin phenol reagent. J. biol. Chem., 193, 265.

McKaY, S. 1975. Experimental staphylococcal infection in the mouse. Ph.D. Thesis, University of Glasgow.

McNiven, A. C., OWEn, P. ANd Arbuthnott, J. P. 1972. Multiple forms of staphylococcal alpha-toxin. J. med. Microbiol., 5, 113.

Russell, R. J., McInroy, R. J., Wilkinson, P. C. AND White, R. G. 1975. Identification of a lipid chemoattractant (chemotactic) factor for macrophages from anaerobic coryneform bacteria. Behring Inst. Mitt., 57, 103.

RyAN, G. B. AND HuRLEY, J. V. 1966. The chemotaxis of polymorphonuclear leucocytes towards damaged tissue. Br. J. exp. Path., 47, 530.

WAdSTRÖM, T., ThelestaM, M. AND MöllBY, R. 1974. Biological properties of extracellular protein from staphylococcus. Ann. N.Y. Acad. Sci., 236, 343.

WALKER, W. S., BARLET, R. L. AND KURTZ, H. M. 1969. Isolation and partial characterisation of a staphylococcal leukocyte cytotaxin. J. Bact., 97, 1005.

Ward, P. A., LePow, I. H. AND Newman, L. J. 1968. Bacterial factors chemotactic for polymorphonuclear leukocytes. Amer. J. Path., 52, 725.

WeKSLER, B. B. AND HILL, M. J. 1969. Inhibition of leukocyte migration by a staphylococcal factor. J. Bact., 98, 1030.

Wilkinson, P. C. 1973. Chemotaxis and inflammation, Edinburgh, p. 168.

Wilkinson, P. C. 1975. Inhibition of leukocyte locomotion and chemotaxis by lipidspecific bacterial toxins. Nature, Lond., 255, 485. 
Wilkinson, P. C., Roberts, J. A., Russell, R. J. ANd McLoughlin, M. M. 1976. Chemotaxis of mitogen-activated human lymphocytes and the effects of membrane active enzymes. Clin. exp. Immun., 25, in the press.

Woodin, A. M. 1971. Leucocidin, DFP, the leucocyte potassium pump and inhibition of chemotaxis. In The reticuloendothelial system and immune phenomena, edited by N. R. diLuzio and K. Fleming (Adv. exp. Med. Biol., vol. 15), New York, p. 71.

Zigmond, S. H. AND HIRSCH, J. G. 1973. Leukocyte locomotion and chemotaxis. New methods for evaluation and demonstration of cell-derived chemotactic factor. J. exp. Med., 137, 387. 